\title{
Role of Manufacturing Flexibility in Enhancing the Customer's Satisfaction- A Case Study on Al- Karwanji / Kirkuk
}

Journal of

\section{TANMIYAT AL- RAFIDAIN}

\section{(TANRA)}

A scientific, quarterly, international, open access, and peer-reviewed journal

Vol. 39, No. 128

Dec., 2020

(C) University of Mosul | College of Administration and Economics, Mosul, Iraq.

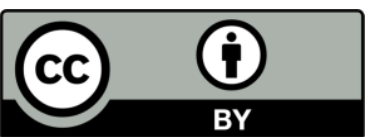

TANRA retain the copyright of published articles, which is released under a "Creative Commons Attribution License for CC-BY-4.0" enabling the unrestricted use, distribution, and reproduction of an article in any medium, provided that the original work is properly cited.

Citation: A. Raoof, Raad and Iswadi Abdullah M. (2020).“Role of Manufacturing Flexibility in Enhancing the Client's SatisfactionA Case Study on Al- Karwanji / Kirkuk. TANMIYAT ALRAFIDAIN， 39 (128), 109-128, https://doi.org/10.33899/tanra.20 20.167371

P-ISSN: 1609-591X e-ISSN: 2664-276X tanmiyat.mosuljournals.com

\author{
Raad Adnan Raouf ${ }^{1}$; Abdullah M. Iswadi ${ }^{2}$ \\ ${ }^{1 \& 2}$ Department of Industrial Management, College of Administration and Economics, \\ University of Mosul
}

Corresponding author: Abdullah M. Iswadi, meaad5810@gmail.com

DOI: 10.33899/tanra.2020.167371

Article History: Received: 30/6/2020; Revised: 23/7 /2020; Accepted: 28/7/2020; Published: $1 / 12 / 2020$.

\begin{abstract}
The research aims to identify the role of manufacturing flexibility as one of the basic ingredients necessary for survival and growth and achieving the competitive advantage of companies in enhancing customer satisfaction as the main goal of all companies in the business world today, due to the increasing intensity of competition and the pursuit of each company to distinguish from its competitors to attract new customers and retain existing customers To this end, the study problem was formulated through a set of questions, the most prominent of which is "What is the role of manufacturing flexibility in enhancing customer satisfaction?"

The research used the questionnaire form to obtain data related to the research field represented by the group of companies Krungi for soft drinks, juices and water located in the governorate of Kirkuk, and a hypothesis form was developed for the research which resulted in a set of hypotheses that have been validated using statistical methods, the most important of which is the Spearman correlation factor within the statistical program (AMOS) To measure the correlation, influence, and variability relationships between study variables, the study reached a set of conclusions, the most important of which are:

"There are a positive correlation and effect between the dimensions of manufacturing flexibility and customer satisfaction" and based on it were presented a set of proposals that contribute to the integrity of the research field.
\end{abstract}

\section{Keywords}

Manufacturing Flexibility, Customer's Satisfaction 


\section{ورقة بحثية

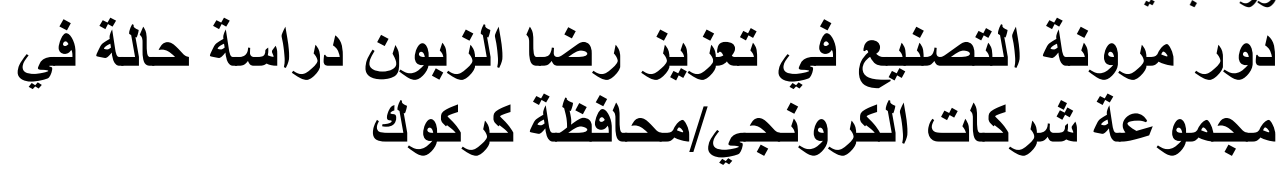

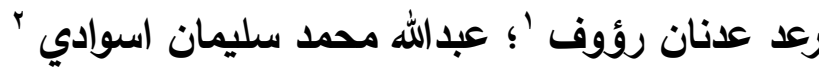

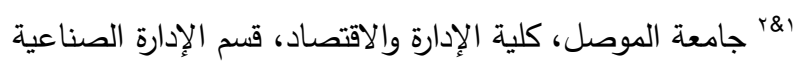

المؤلف المراسل: عبدالله محمد سليمان اسوادي ، meaad5810@gmail.com DOI: 10.33899/tanra.2020.167371

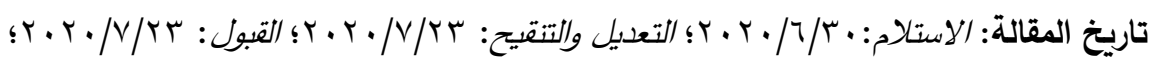

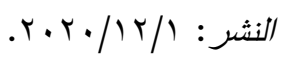

المستخلص

يهذف البحث التعرف على دور مرونة التصنيع بوصفها أحد الدقومات الأساسية اللازمة للبقاء والندو وتحقيق

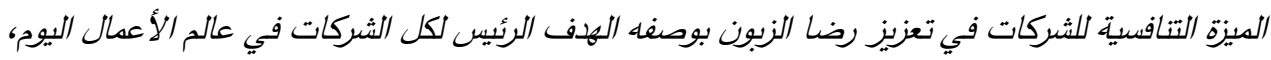

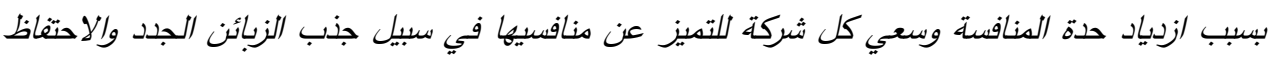

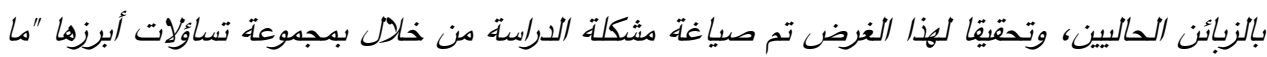

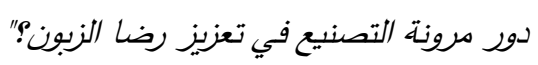

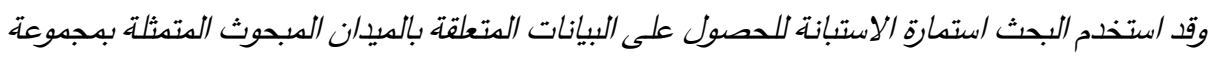

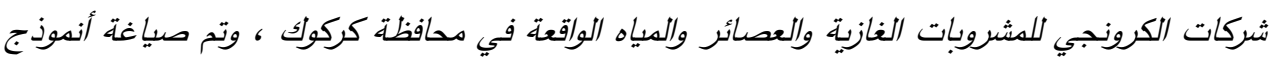

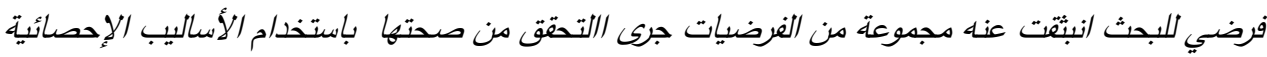
أهها معامل ارتباط سبيرمان ضنن البرنامج الاحصائي (AMOS) لقياس علاقات الارتباط والتأثير والتباين بين متغيرات الدراسة، وتوصلت الدراسة إلى مجموعة من الاستنتاجات أهدها:

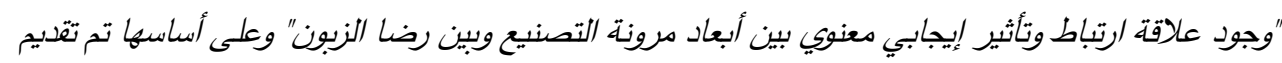
مجوعة من الدقترحات التي تسهم في حدمة العيدان المبحوث.

الكلمات المفتاحية مرونة التصنيع، رضا الزبون

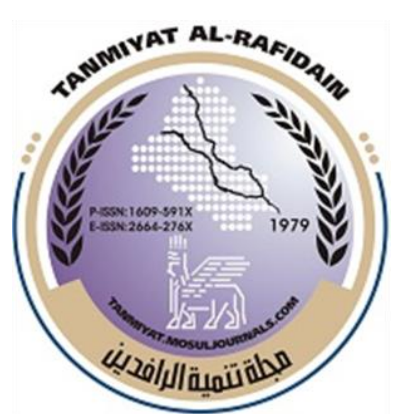

\section{هبلة}

\section{تنسيهية الرافدين}

(TANRA) دولية، مفتوحة الوصول، محكمة.

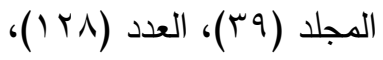

$$
\begin{aligned}
& \text { كانون الاول .r.r. }
\end{aligned}
$$
كلية الإدارة والاقتصاد، الموصل، العراق.

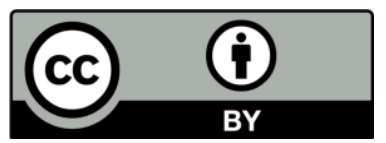

تحتفظ (TANRA) بحقوق الطبع والنشر للمقالات المنشورة، والتي يتم إصدارها بموجب ترخيص ولنش \lrcorner (Creative Commons Attribution) (CC-BY-4.0)

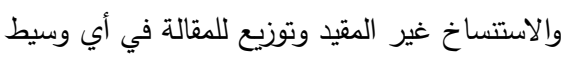
نقل، بشرط اقتباس العمل الأصلي بشكل صحيح.

الاقتباس: رؤوف، رعد عدنان و اسوادي،

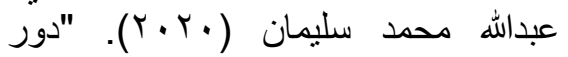
مرونة التصنيع في تعزيز رضان الزيا الزبون

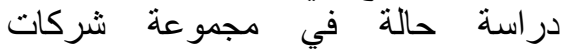

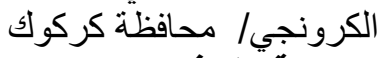

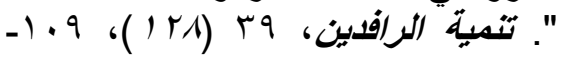
https://doi.org/10.33899/tanra.20 20.167371

P-ISSN: 1609-591X e-ISSN: 2664-276X tanmiyat.mosuljournals.com 


\section{المبحث الأول - منهجية البحث}

\section{أولاًا : مشكلة البحث}

يمثل تقديم منتجات ذات جودة عالية الهدف الأساس الذي تسعى معظم الشركات إلى تحقيقه ، ويعد هذا الهدف الدافع الأساس الذي تقوم من أجله الشركات على نحو عام ومجموعة شركات الكرونجي ميدان البحث

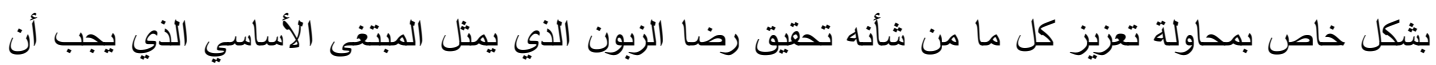
تسعى الشركات للوصول إليه.

\section{وقد تبلورت مشكلة البحث من خلال تحديد الفجوات الآتية:}

أولا : الفجوة المعرفية

من خلال اطلاع الباحثين على الدراسات المرجعية التي تتاولت متعيرات البحث الحالي ومنها دراسات

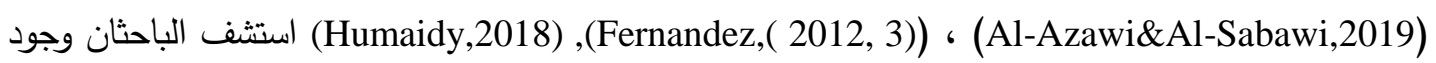
فجوة معرفية، إذ لم تختبر الدراسات السابقة ( في حدود اطلاع الباحثين) قدرة مرونة التصنيع في تعزيز رضا

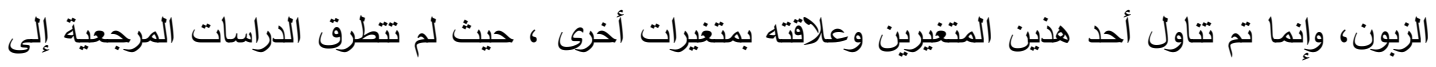
دور مرونة التصنيع في تعزيز رضا الزبون على الرغم من العلاقة المنطقية بينهما على اعتبار أن مرونة التصنيع تسمح بتلبية رغبات الزبون في الحصول على المواصفات التي يرغب وجودها في المنتج، الأمر الذي يسهر في تعزيز حالة الرضا لديه ،وبالتالي فالبحث الحالي يمثل إسهامة في ردم تلك الفجوة.

ثانيا: الفجوة الميدانية

تأشر لدى الباحثين ومن خلال الزيارات الاستطلاعية التي قاما بها لمجموعة شركات الكرونجي في محافظة

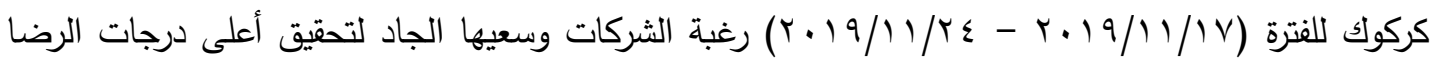
للزبون مستندة إلى ما تمتلكه من مقومات مرونة التصنيع من مكائن ومعدات تتسم بقدرتها الكبيرة في تتويع

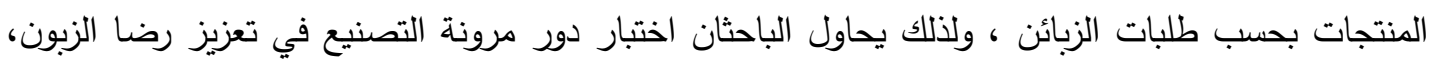
واتساقاً مع ما تقدم فان طرح التساؤلات المؤشرة أدناه يمكن أن تسهم في تحديد المشكلة

1- هل تمتلك الثركات المبحوثة مقومات مرونة التصنيع ؟ هل r- هل هناك تصور واضح لدى العاملين في الشركات المبحوثة عن مستويات الرضا لزبائن الشركات؟

$$
\begin{aligned}
& \text { ץ- ما دور مرونة التصنيع في تعزيز رضا الزبون؟ } \\
& \text { ثانيا: أهمية البحث: } \\
& \text { تبرز أهمية البحث الحالي ضمن الجوانب الآتية: }
\end{aligned}
$$




\section{رؤوف وسليمان}

ا ـ الجانب النظري: تتجسد أهمية البحث أكاديمياً في أهمية المتغيرات التي تتاولاها بهدف إثراء مكتبة جامعة الموصل بصورة خاصة والمكتبات العراقية بصورة عامة بالمفاهيم الحديثة ضمن إطار نظري وتطبيقي

$$
\text { لعلاقة رضا الزبون في ظل مرونة التصنيع. }
$$

r. الجانب الميداني: تقديم اطار نظري وتطبيقي للشركة المبحوثة حول الية استخدام مرونة التصنيع لتعزيز رضا الزبون من خلال توضيح علاقة الارتباط والأثر بين مرونة التصنيع بأبعاده(مرونة العميلة ، مرونة لهنة

$$
\text { ثالثا: أهداف البحث: المكائن والالات، المنتج، الحجم ) ورضا الزبون. }
$$

يسعى البحث إلى تحقيق جملة من الأهداف تتمثل بما يأتي: ا. وضع إطار نظري يوضح متغيرات البحث المتمثلة بالمرونة التصنيعية ورضا الزبون عن المنتجات

$$
\text { المقدمة له في ظل اعتماد تلك الأبعاد. }
$$

r. وصف وتثخيص مستوى تحقق متغيرات البحث المتمثلة بـ (مرونة التصنيع ورضا الزبون)

$$
\text { r. ب. بان تأثير مرونة التصنيع في رضا الزبون. }
$$

$$
\text { رابعاً: مخطط البحث الافتراضي: }
$$

تتطلب المعالجة المنهجية لمشكلة البحث، بناء مخطط افتراضي يعبر عن العلاقة بين المتغيرات الرئيسة والفرعية، التي تثير إلى تصورات وإجابات أولية لفرضياتها، إذ يشمل المخطط مجموعة العلاقات المنطقية التي لناه قد تكون في صورة كمية أو كيفية، وتجمع معها الملامح الرئيسة للواقع الذي تهتم به، ولقد تبنى البحث في دراسته لدئه العلاقة والتأثير بين مرونة التصنيع ورضا الزبون، ويبين الثكل (1) مخطط البحث الافتراضي.

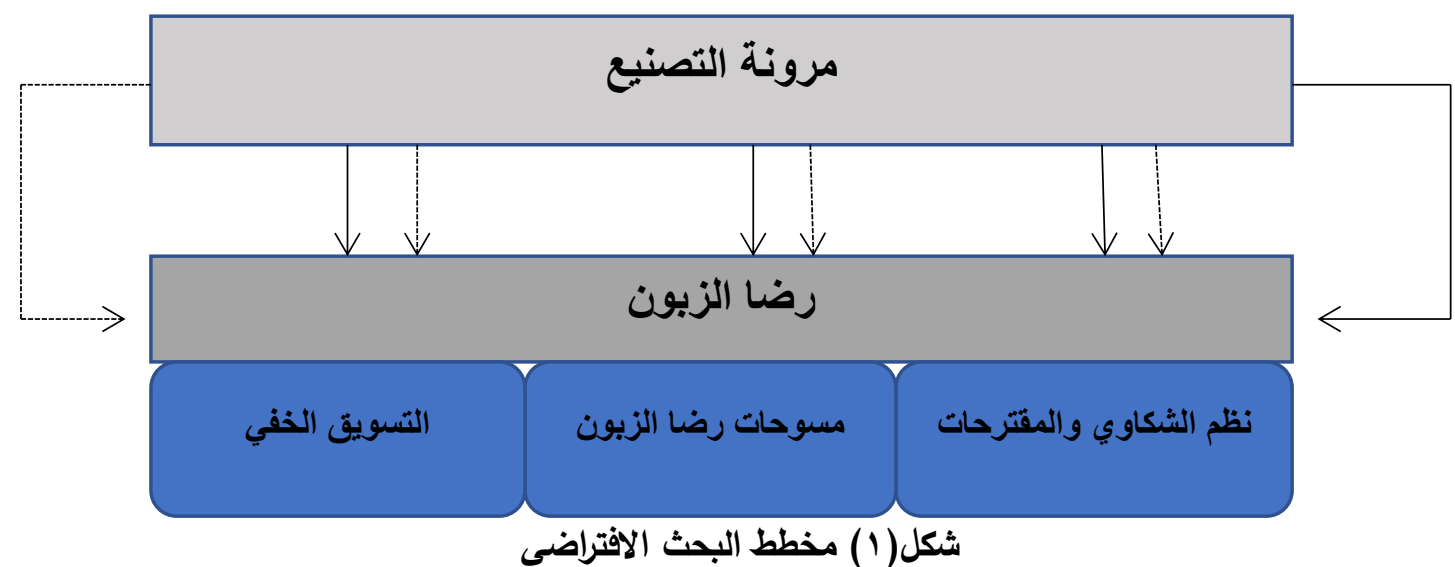


المبحث الأول - مرونة التصنيع

أولاً: مفهوم مرونة التصنيع

مرونة التصنيع هي القدرة على مواجهة الظروف والمتطلبات البيئية المتغيرة للعملية والتكييف معها

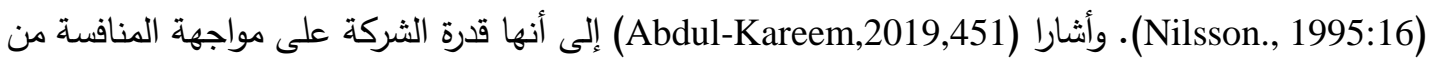
خلال إمكانية إجراء التغيرات سواءً في العاملين أو عمليات الانتاج أو تغيير المنتجات بالثكل الذي يحقق أعلى الثى

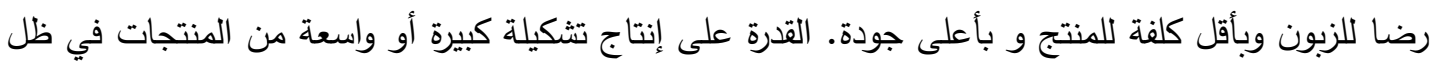
الظروف المتغيرة للاسواق وتغييرات في طلبات الزبائن(Al-Azawi\&Al-Sabawi,2019,219 ). هي إحدى طرائق تحسين جودة الأداء وجودة المنتجات أو هي القدرة على تطوير واختيار البدائل لموقف معين أو قدرة نظام التصنيع على تطوير واختيار البدائل لانتاج منتجات متتوعة تواكب متطلبات السوق(Nayak.,at al.,2013,29). ثانيا: أهمية مرونة التصنيع

ازدادت أهمية مرونة التصنيع في إدارة الإنتاج والعمليات بسبب طبيعة التغيير الذي حدث في بيئة الأعمال والتي أثرت في شكل المنافسة ، والتي تعتمد بثكل كبير على التحسين المستمر للخصائص التقنية للمنتجات

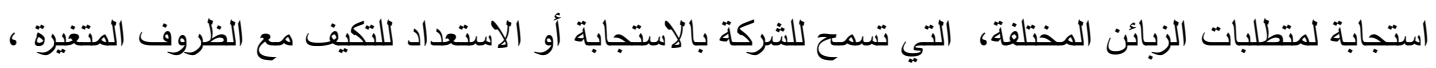
إذ إن الظروف المتغيرة هنا قد تكون سرعة التغيير في احتياجات الزبائن أو التقلبات في توافر المواد الخام

.(Beckman, 2008, 383-384)

وأضاف ( Al-Lamy,2014,61 بأن أهمية مرونة التصنيع تتمثل بالآتي:

1- زيادة قدرة الشركة في الاستجابة للتغيرات المختلفة التي تحصل في بيئة الأعمال من خلال قابلية نظام

$$
\text { الانتاج على التكيف مع الظروف الجديدة. }
$$

r- مساهمة أبعاد مرونة التصنيع في المحافظة على نتائج الأداء النهائي لنظام الانتاج وبالثكل الذي يؤدي إلى تعزيز القدرة التتافسية للشركة. r- محافظة مرونة التصنيع على الكلفة والوقت عند إجراء تغيير في نظام الانتاج سواء كان في زيادة حجم الانتاج أو إضافة منتجات جديدة مرونه ع- تمكن الثركة من مواجهة المنافسة التي تحصل في بيئة الأعمال من خلال مواكبة التطورات عبر تقديم منتجات جديدة أو تحديث المنتجات الحالية. ه- تمنح نظام الانتاج القدرة على تجاوز العطلات أو التوقفات التي تحصل في بعض أجزاء أو مواقع الانتاج عبر استخدام معدات أو مسارات بديلة وبالتالي الاستمرار في عملية الانتاج. 


\section{رؤوف وسليمان}

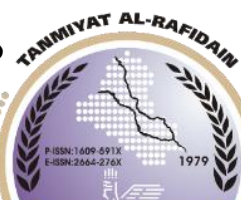

ثالثا: أهداف مرونة التصنيع

من خلال زيادة المرونة في مجال التصنيع يمكن تحقيق الأهداف الاتيه (Ngamsirijit, 2008, 38-39) ا. تطوير فهم شامل عن التخطيط الإستراتيجي والخطط التشغيلية الحالية وتحديد المخاوف عند تتفيذ عمليات

التصنيع.

ז. تحليل القضايا الرئيسة أو آليات حاسمة لأداء المرونة و القضايا الأخرى المتعلقة بتحسين المرونة مثل العقبات

$$
\text { والقدرات. }
$$

r. تطوير واختبار إطار صنع القرار وأداة تقديم القرار والعوامل الرئيسة التي يتعين مراعاتها من أجل تسهيل

$$
\text { تحسين المرونة. }
$$

وأضاف (Nayak.,at al.,2013:34) الأهداف الاتية

1- سهولة تحويل الأجزاء واستخدام الاتمتة المبرمجة وإهائة

r- تقليل وقت التهيئة والإعداد وصفوف الانتظار ، إذ تكون الالات جاهزة للمعالجة r- تقليل المخزون تحت الصنع إلى حوالي • ٪\%، لأن عمليات التصنيع تكون جاهزة فور انتهاء القطعة

\section{السابقة.}

$$
\begin{aligned}
& \text { ع- يسمح بالاستجابة بشكل أسرع للمنتجات الجديدة والتغيير في الطلب وإنجاز العمليات الضرورية. } \\
& \text { 0- تقليل الكلف نتيجة السرعة في إنجاز العمليات وتحسين المركز التتافسي للشركة. } \\
& \text { 1- يهدف لانتاج منتجات متتوعة وبأحجام متوسطة وبسرعة مناسبة وبجودة مناسبة. } \\
& \text { رابعا: أبعاد مرونة التصنيع }
\end{aligned}
$$

تعني خطط وعمليات مختلفة لإنتاج الجزء نفسه (المنتج)، مما يعني القدرة على تغيير ترتيب عمليات الانتاج (Al-Azawi\&Al-Sabawi,2019,216،). فهي تشير إلى القدرة على إجراء تغيير أثناء عملية الإنتاج لتوفير منتجات مختلفة بأقل قدر من التأخير ، وهذا يعني تقديم مجموعة مختلفة من المنتجات المحددة باستخدام

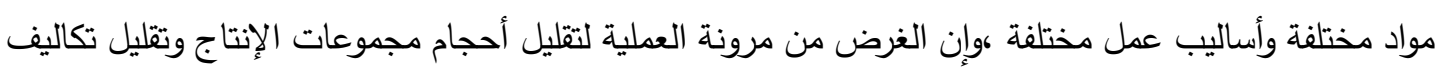
المخزون(Parker \& Wirth, 1998, 430-433) • ويعرف كل من (Stockton \& Bateman, 1995, 28) مرونة من مونة العملية على أنها مجموعة من الأنواع المختلفة من المنتجات التي يمكن لنظام الإنتاج توفيرها من دون إعداد

$$
\text { وتحضير أوليين. }
$$

Volume flexibility مرونة الحجم اونين.

يمكن تعريف مرونة الحجم على أنها تعبير عن قدرة نظام التصنيع على العمل بشكل مربح على مستويات مختلفة من إجمالي الإنتاج ، مما يسمح للشركة بزيادة أو خفض إجمالي حجم الإنتاج بطريقة مناسبة للتغير في 
طلب الزبائن (Sethi and Seth, 1990) • وتعرف على أنها القدرة على تغيير مستويات المخرجات بمعنى استيعاب أكبر عدد من الزبائن وكذلك تقديم منتجات أكثر بحيث تكفي كل احتياجات الزبائن

(Mahmood,2016,70)

Flexibility machines برونة المكائن ويشير (Khoobiyan, et al.,2017,558) إلى مرونة المكائن على أنها القدرة على أداء مختلف العمليات عن طريق ذات الماكنة دون الحاجة إلى إنفاق الكثير من الوقت والكلفة للانتقال من عملية واحدة إلى أخرى. في حين عرفها (Pramod and Garg, 2006, 200) على أنها تثير إلى الأنواع المختلفة من العمليات التي يمكن أن تقوم بها الماكنة من دون الحاجة إلى بذل جهود غير مدكنة للتبديل من عملية إلى أخرى.

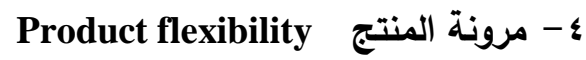

وتثير مرونة المنتج إلى السهولة التي يمكن بها تغيير المواصفات التي أدخلت حديثا على المنتجات

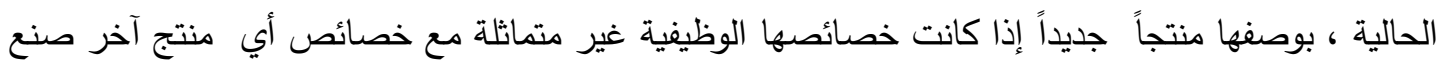

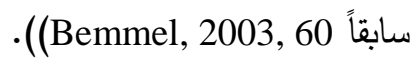

\section{New Product Flexibility مرونة المنتج الجديد}

يثير إلى المنتجات الجديدة التي أدخلت من نظام الإنتاج ، والتي تتميز بعدم التجانس ودون أن يتحمل نظام الإنتاج تكاليف نقل عالية عند التبديل من منتج إلى آخر ، أو التأثير على نتائج الأداء الكلي لنظام الإنتاج. يعكس مفهوم المنتج الجديد المنتج الذي له خصائص وظيفية تختلف عن المنتجات الحالية (Al-)

(Faraan,2007,60

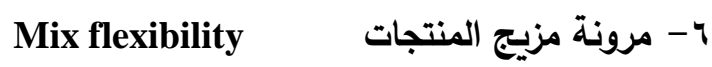

ويعبر عن القدرة على تصنيع منتجات متعددة بالمقدار نفسه من الطاقة. نلاحظ هنا التركيز على علاقة الطاقة بمرونة المزيج (Goyal \& Netessine, 2010, 2) • وركز (Slack \& Correa, 1992, 85) على الوقت بوصفه عنصراً مهماً يرتبط بمرونة المزيج وبأنه قادر على توفير تتوعاً كبيرا من المنتجات في مدة زمنية محددة.

$$
\text { المبحث الثاني: رضا الزبون }
$$

عرف الرضا في ضوء الحكم الموضوعي الذي يقوم به الزبون بغض النظر عن الحالة الداخلية والنفسية

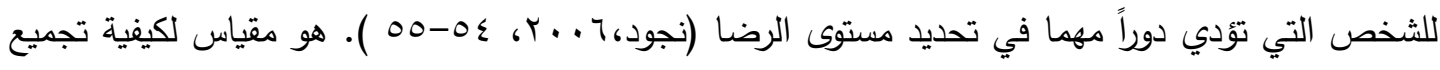

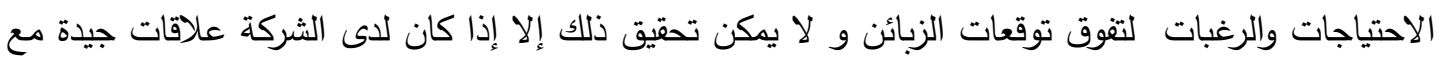
جميع اصحاب العلاقة في سوق الأعمال(AL-Afandy,2018,43)

TANMIYAT AL-RAFIDAIN (P-ISSN: 1609-591X; E-ISSN: 2664-276X) تنمية الرافدين 


\section{رؤوف وسليمان} \\ -}

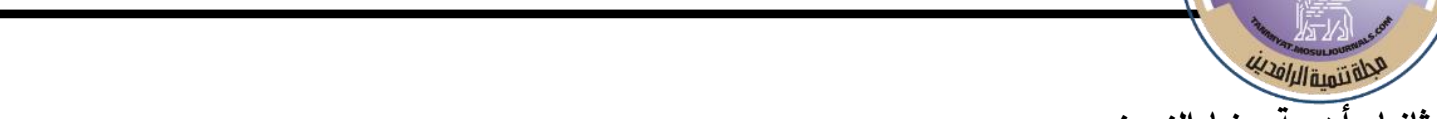

يعد رضا الزبون أهم الأولويات التي تسعى الشركات لتحقيقها، لأنه يعد أحد الضمانات الأساسية لبقائها،

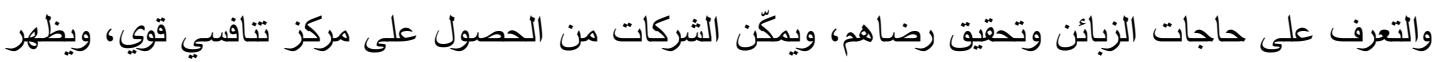

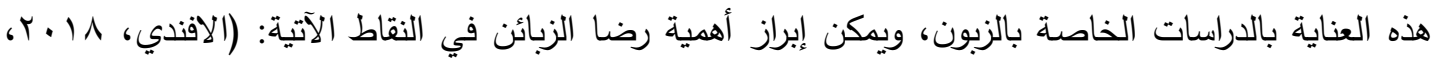

1- تمكين الثركة من البقاء والاستمرار في السوق وتحقيق الربحية عن طريق كسب رضا الزبائن

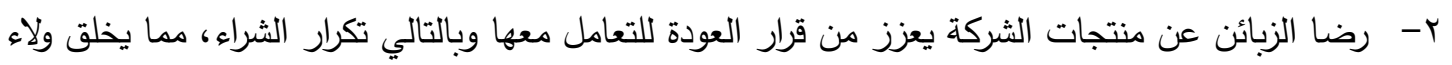

$$
\text { ثالثا: خطوات تحقيق رضا الزبون الزبون لـنجات الثركة. }
$$

يتأثر رضا الزبون بشكل كبير بالعديد من العوامل الداخلية والخارجية، إذ إن عملية تغيير رضا الزبون وعدم رضاه يستلزم من الثركات التي تعتتي بالزبون وبكيفية إرضائه إيجاد طرائق لمراقبة الرضا وقياسه وبشكل

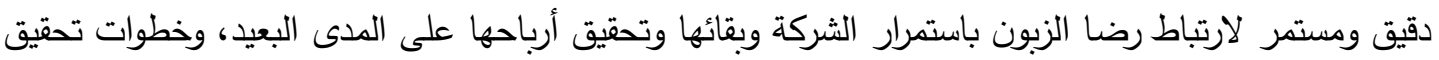
الرضا تتمثل بالآتي: (Hamad,2018,475) 1- فهم حاجات الزبون: ومعناه اتصال الثركة الدائم بالزبون سواء الحالي أو المحتمل لمعرفة العوامل التي تحدد السلوك الشرائي لهذا الزبون. ץ- التغذية العكسية للزبون : وتتمثل في الطرائق والأساليب التي يستخدمها المسوقون لتعقب آراء الزبون عن الثركة لمعرفة مدى تلبيتها لتوقعاته. r- القياس المستمر : أي قيام الثركة بإنشاء برنامج خاص لقياس رضا الزبون مثل نظام ( customer

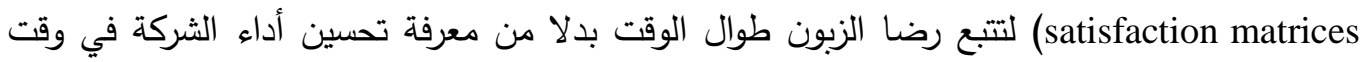

$$
\begin{aligned}
& \text { معين. } \\
& \text { رابعاً: أبعاد رضا الزبون } \\
& \text { 1- نظم الثكاوى والمقترحات }
\end{aligned}
$$

تعمل الثركة الموجهة للزبون على تسهيل قدرة زبائنها لتقديم اقتراحاتهم وشكاواهم عن طريق إنثاء خطوط اتصال هاتفية مجانية ، فضلاً عن استخدام البريد الإكتروني من خلال الموقع الإلكتروني لتحقيق السرعة

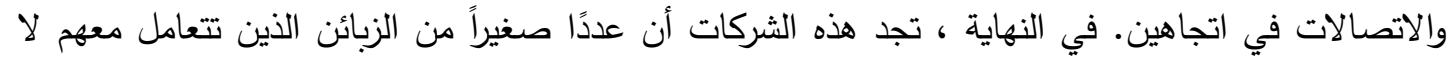
يكلف الثركة كثيراً ، لكنهم يحققون أرباحًا عالية. هذا ناتج عن طبيعة الخدمات ونظام توزيع المنتجات المقدمة لهؤلاء الزبائن، إذ كانت تكاليفهم أقل موازنة بالإيرادات المحققة ، وبناءً على هذه النتيجة ، لجأت الكثير من 
الثركات إلى التغيير نحو التسويق عبر الهاتف أو الإنترنت بوصفها وسيلة حديثة ومتطورة لخدمة عدد من الزبائن

.(AL-taee,2009,25)

$$
\text { r - ب مسوحات رضا الزبون }
$$

أظهرت الدراسات أن هناك عملية واحدة من كل أربع عمليات يقوم بها الفرد لإظهار أن الزبون غير راضٍ، ولكن عدد الزبائن غير الراضين في تقديم الثكاوى والمقترحات لا يتجاوز ه ٪. وبالتالي ، فإن معظم الزبائن يغيرون هذه الشركات التي يتعاملون معها أو يطلبون منتجات أقل منهم. لذلك فإن أنظمة الثكاوى لتهي

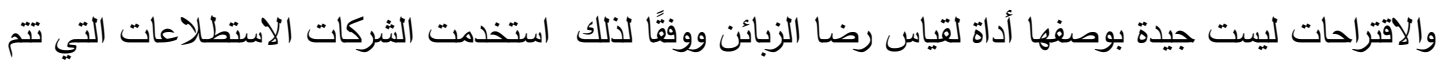
بشكل مباشر عن طريق استكمال الاستبيانات الدورية ، على سبيل المثال (أربع مرات في السنة) لقياس رضا لـان الزبائن، ومدى قناعة الزبون ورضاه عن ذلك أم لا. (Kotler, 2000 ( 47).

$$
\text { ب- التسوق الخفي }
$$

يمكن للشركة استخدام الأفراد الذين يعملون بوصفهم مشترين وإبلاغ الإدارة عن نقاط القوة والضعف التي

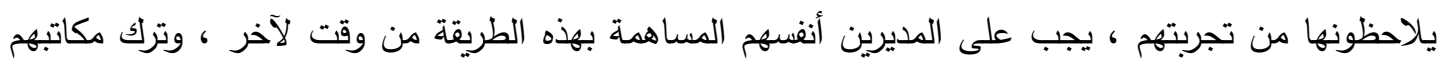
لعرض أماكن مبيعات الثركة وأماكن بيع المنافسين دون الكثف عن هوياتهم ، وإعداد العلاجات التي يرونها،

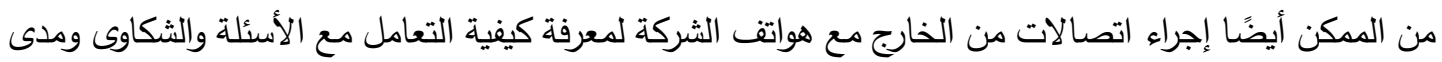
سرعة الاستجابة رداً على الزبائن.(AL-Mohtady,2002,65).

$$
\text { أولاً: وصث الثالث: الجانب الميداني }
$$

يتضمن هذا المبحث وصف جميع متغيرات البحث وتثخيصها من أجل الوقوف على نقاط القوة والضعف

$$
\text { في الشركة المبحوثة، وذلك وفق الآتي : }
$$

\section{ا- - وصف أبعاد مرونة التصنيع وتثخيصها ودئه التهي}

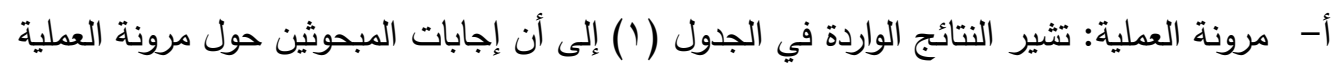

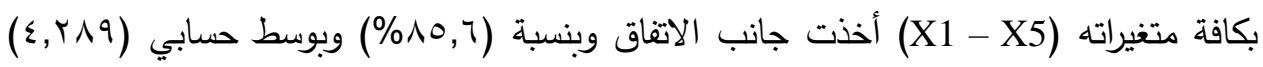

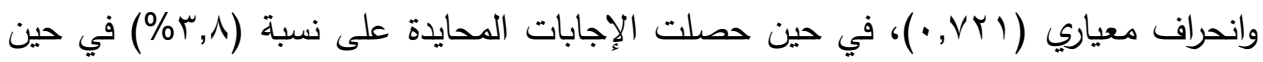

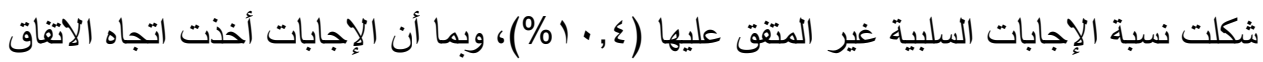
فإن المتغير الذي أسهم في إغناء نسبة الاتفاق هو (X1) والذي ينص على (يمكن لنظام الانتاج تقديم مجموعة من المنتجات من دون تهيئة وإعداد مسبقين) والذي حقق أعلى نسبة اتفاق تقدر 
رؤوف وسليمان

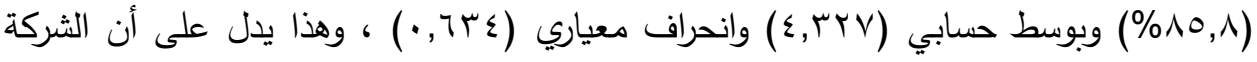

المبحوثة تقوم بإنتاج منتجات متتوعة دون عملية تهيئة مسبقة.

الجدول (1): يبين التوزيعات التكرارية والنسب المئوية والأوساط الحسابية والانحرافات المعيارية لإجابات

المبحوثين حول مرونة العملية

\begin{tabular}{|c|c|c|c|c|c|c|c|c|c|c|c|c|}
\hline \multicolumn{12}{|c|}{ مقياس الاستجابة } & \multirow{3}{*}{ المتغيرات } \\
\hline \multirow{2}{*}{ المعياري } & \multirow{2}{*}{ الوسط الحسابي } & \multicolumn{2}{|c|}{ لا اتفق بثدة ا } & \multicolumn{2}{|c|}{ لا اتفق r } & \multicolumn{2}{|c|}{ محايد r } & \multicolumn{2}{|c|}{ اتفق ؛ } & \multicolumn{2}{|c|}{ اتفق بشدة هـ } & \\
\hline & & $\%$ & ت & $\%$ & 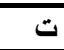 & $\%$ & 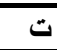 & $\%$ & ت & $\%$ & 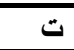 & \\
\hline • & $\varepsilon, M Y V$ & 7 & 11 & $\varepsilon, 7$ & $1 \varepsilon$ & $r, \tau$ & 11 & $r V, 0$ & NT & $0 \wedge, r$ & $1 V 7$ & $\mathrm{X} 1$ \\
\hline r TAK & $\varepsilon, r q \wedge$ & $0, r$ & 17 & $0, r$ & 17 & $r, \tau$ & 11 & $r_{0,1}$ & VA & 09,9 & $|1|$ & $\mathrm{x} 2$ \\
\hline$\cdot, \vee \vee \vee$ & $\varepsilon, Y \wedge \varepsilon$ & 0 & 10 & 0,7 & IV & $\varepsilon, r$ & r & $r \uparrow, r$ & $v q$ & $0 \wedge, 9$ & $1 \vee \wedge$ & $\times 3$ \\
\hline • ATr & $\varepsilon, r V \varepsilon$ & $\varepsilon$ & ir & 7,7 & $r$. & $r, \tau$ & 11 & $r \leqslant, r$ & $V^{T}$ & T, & 114 & $\mathrm{X} 4$ \\
\hline . TVI & $\varepsilon, Y\rceil \varepsilon$ & $\varepsilon, r$ & 15 & 0,7 & iv & $\varepsilon, r$ & $\pi$ & $r \cdot, \Lambda$ & ז9 & 00 & 177 & $\times 5$ \\
\hline \multirow{2}{*}{$\cdot, V Y)$} & \multirow{2}{*}{$\varepsilon, Y \wedge q$} & $\varepsilon, 9$ & & 0,0 & & $r, \Lambda$ & & rq, 9 & & $O \Lambda, V$ & & المعدل \\
\hline & & & & & $\sqrt{\cdot, \xi}$ & & $\overline{r, \Lambda}$ & & & & 10,7 & المجموع \\
\hline
\end{tabular}

الجدول من إعداد الباحث بالاعتماد على برنامج (SPSS)

ب- مرونة الحجم: تشير النتائج الواردة في الجدول (r) إلى أن إجابات المبحوثين حول مرونة الحجم

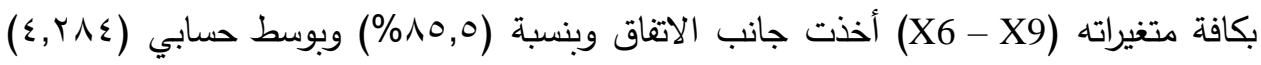

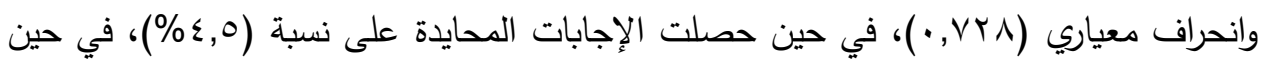

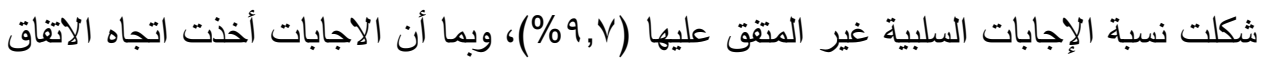
فإن المتغير الذي أسهم في إغناء نسبة الاتفاق هو (X6) والذي ينص على الآتي (يمكن تحقيق

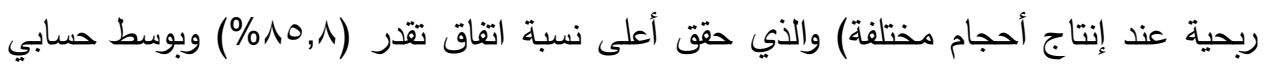

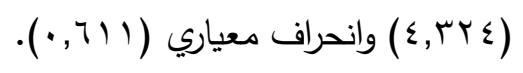




\section{رؤوف وسليمان}

الجدول (ץ): يبين التوزيعات التكرارية والنسب المئوية والاوساط الحسابية والانحرافات المعيارية لإجابات المبحوثين حول مرونة الحجم

\begin{tabular}{|c|c|c|c|c|c|c|c|c|c|c|c|c|}
\hline \multicolumn{12}{|c|}{ مقياس الاستجابة } & \multirow{3}{*}{ المتغيرات } \\
\hline \multirow{2}{*}{ الانحراف } & \multirow{2}{*}{ الوسطابي الحسي } & \multicolumn{2}{|c|}{ لااتفق بثدة } & \multicolumn{2}{|c|}{ لا اتفق } & \multicolumn{2}{|c|}{ محايد } & \multicolumn{2}{|c|}{ اتفق } & \multicolumn{2}{|c|}{ اتفق بشدة } & \\
\hline & & $\%$ & ت & $\%$ & ت & $\%$ & $ت$ & $\%$ & ت & $\%$ & ت & \\
\hline$\cdot, 711$ & $\leq, r Y \leq$ & r & 9 & T, & 19 & 0 & 10 & ب & 111 & $\leqslant 9$ & $1 \leq \wedge$ & X6 \\
\hline$\cdot, \vee \wedge \wedge$ & $\varepsilon, r \cdot v$ & $\varepsilon, r$ & r & 0,7 & IV & $\varepsilon, 7$ & $1 \leq$ & YO, & vı & 09,7 & 11. & $\mathrm{X} 7$ \\
\hline$\cdot$, Vor & $\varepsilon, Y_{Y}$ & $r, \tau$ & 11 & 7 & 11 & $\varepsilon\rceil$, & $1 \varepsilon$ & $r_{0, \Lambda}$ & VA & 09,9 & $|1|$ & $\mathrm{X} 8$ \\
\hline$\cdot, \vee>1)$ & $\varepsilon, Y \wedge)$ & $\varepsilon$ & Ir & $7, \Gamma$ & 19 & $\varepsilon$ & IT & $r q, 1$ & $\wedge \wedge$ & 07,7 & $|V|$ & X9 \\
\hline \multirow{2}{*}{$\cdot, \vee Y \wedge$} & \multirow{2}{*}{$\varepsilon, Y \wedge \varepsilon$} & $r, v$ & & 7 & & $\varepsilon, 0$ & & $r q, r$ & & $\Delta 7, r$ & & المعدل \\
\hline & & \multicolumn{4}{|c|}{$q, v$} & \multicolumn{2}{|c|}{$\varepsilon, 0$} & \multicolumn{4}{|c|}{$\Lambda \bullet, 0$} & المجموع \\
\hline
\end{tabular}

الجدول من إعداد الباحث بالاعتماد على برنامج (SPSS)

ج- مرونة المكائن: تشير النتائج الواردة في الجدول (r) إن إجابات المبحوثين حول مرونة المكائن بكافة

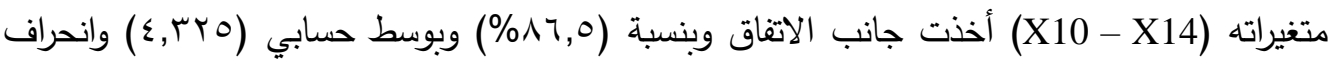

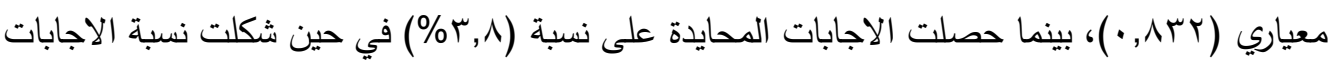
السلبية غير المتقق عليها (9,9\%)، وبما أن الإجابات أخذت اتجاه الاتفاق فان المتغير الذي أسهم في إغناء نسبة الاتفاق هو (X13) والذي ينص على (يمكن للمكائن الانتقال من عملية إلى أخرى دون تحمل

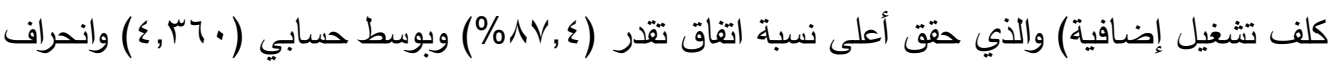

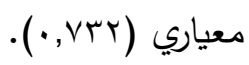
الجدول (ץ): يبين التوزيعات التكرارية والنسب المئوية والأوساط الحسابية والانحرافات المعيارية لإجابات المبحوثين حول مرونة المكائن

\begin{tabular}{|c|c|c|c|c|c|c|c|c|c|c|c|c|}
\hline \multicolumn{12}{|c|}{ مقياس الاستجابة } & \multirow{3}{*}{ المتغيرات } \\
\hline \multirow{2}{*}{ الانحراف } & \multirow{2}{*}{ الوسط الحسبي } & \multicolumn{2}{|c|}{ لا اتفق بثدة } & \multicolumn{2}{|c|}{ لا اتفق } & \multicolumn{2}{|c|}{ محايد } & \multicolumn{2}{|c|}{ اتفق } & \multicolumn{2}{|c|}{ اتفق بشدة } & \\
\hline & & $\%$ & $ت$ & $\%$ & $ت$ & $\%$ & $ت$ & $\%$ & $ت$ & $\%$ & $ت$ & \\
\hline$\cdot, \wedge \wedge \mid$ & $\varepsilon, \Gamma \leq V$ & $r, T$ & 11 & 7,7 & $r$. & $r, r$ & $\wedge$ & $r_{0,0}$ & $V V$ & 71,7 & 114 & $\mathrm{X} 10$ \\
\hline . & $\varepsilon, \Gamma)$ & $\varepsilon$ & IT & 0,7 & IV & $\varepsilon, 7$ & $1 \varepsilon$ & $r \uparrow, \wedge$ & 1) & $0 \wedge, q$ & $i v \wedge$ & $\mathrm{X} 11$ \\
\hline$\cdot, 100$ & $\varepsilon, T Y \varepsilon$ & $r, \tau$ & 11 & 7 & 11 & $\varepsilon, r$ & ir & $r \uparrow, 0$ & $\wedge$. & 09,7 & 11. & $\mathrm{X} 12$ \\
\hline •, VTr & $\varepsilon$, & $r, r$ & 1. & 0,7 & IV & $r, r$ & 11 & $r \uparrow, 0$ & $\wedge$. & $7 \cdot, 9$ & $1 \wedge \varepsilon$ & X13 \\
\hline$\cdot, \wedge Y q$ & $\varepsilon, Y \wedge \varepsilon$ & $r, r$ & 1. & $7, r$ & 19 & $\varepsilon$ & Ir & $r_{1,0}$ & 90 & 00 & 174 & $\mathrm{X} 14$ \\
\hline 促 & O & $r, 0$ & & $7,$. & & $r, \wedge$ & & $r v, r$ & & $\Delta q, r$ & & المعدل \\
\hline
\end{tabular}




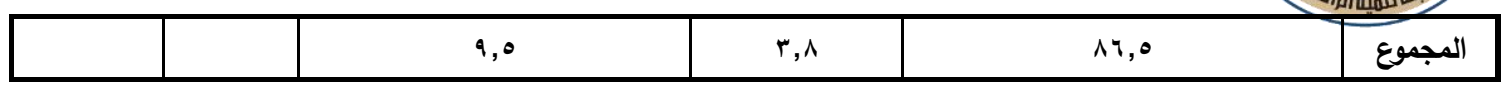

الجدول من إعداد الباحث بالاعتماد على برنامج (SPSS)

د- درونة المنتج: تثير النتائج الواردة في الجدول (ع) إلى أن إجابات المبحوثين حول مرونة المنتج

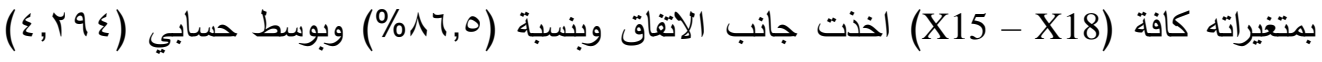

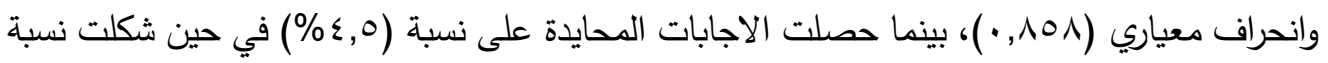
الاجابات السلبية غير المتفق عليها (9\%)، وبما أن الإجابات أخذت اتجاه الاتفاق فإن المتغير الذي أسهم في إغناء نسبة الاتفاق هو (X17) والذي ينص على الآتي (لا يتاثر أداء نظام التصنيع بالتغير

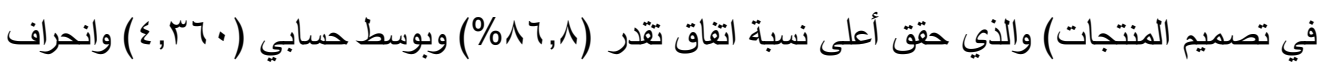

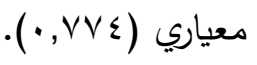

الجدول (؛): يبين التوزيعات التكرارية والنسب المئوية والأوساط الحسابية والانحرافات المعيارية لاجابات

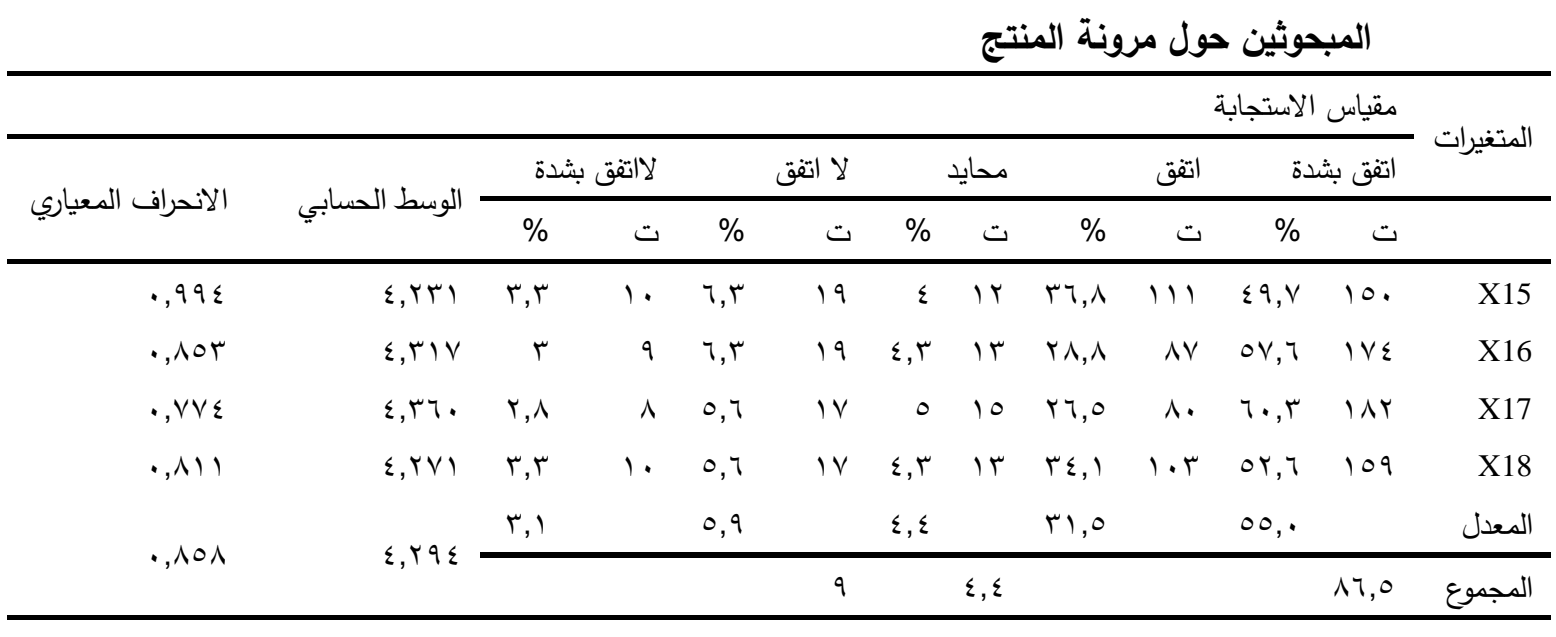

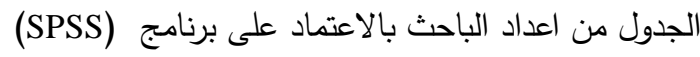

\section{r- r - وصف أبعاد رضا الزبون وتشخيصها}

أ- شكاوي الزبائن: تثير النتائج الواردة في الجدول (0) إلى أن إجابات المبحوثين حول شكاوى الزبائن

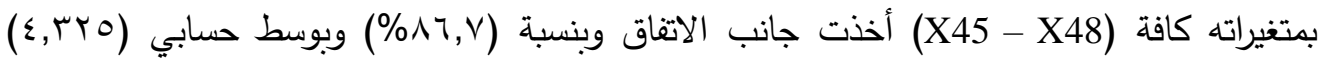

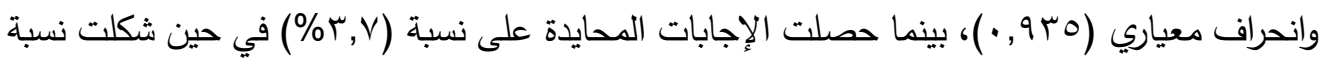

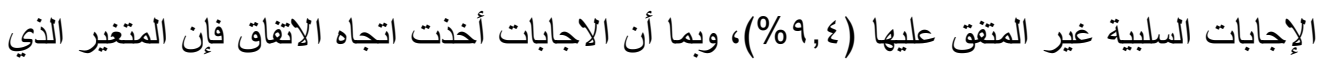


رؤوف وسليمان

أسهم في إغناء نسبة الاتفاق هو (X47) والذي ينص على الآتي (يتم فتح صندوق الثكاوى دوريا من

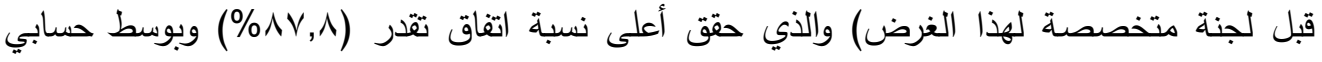

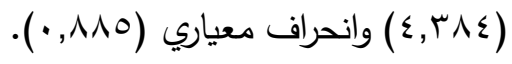

جدول (0): يبين التوزيعات التكرارية والنسب المئوية والأوساط الحسابية والانحرافات المعيارية لاجابات المبحوثين حول شكاوى الزبائن

\begin{tabular}{|c|c|c|c|c|c|c|c|c|c|c|c|c|}
\hline \multicolumn{12}{|c|}{ مقياس الاستجابة } & \multirow{3}{*}{ المتغيرات } \\
\hline \multirow{2}{*}{ الانحراف } & \multirow{2}{*}{ الوسط } & \multicolumn{2}{|c|}{ لاتفق بشدة } & \multicolumn{2}{|c|}{ لا اتفق } & \multicolumn{2}{|c|}{ محايد } & \multicolumn{2}{|c|}{ اتفق } & \multicolumn{2}{|c|}{ اتفق بشدة } & \\
\hline & & $\%$ & ت & $\%$ & $ت$ & $\%$ & ت & $\%$ & ت & $\%$ & ت & \\
\hline$\cdot, 97 \leq$ & $\varepsilon, Y \wedge \Lambda$ & $\varepsilon$ & Ir & 7 & 11 & r, & 1. & $r \cdot, \Lambda$ & 9 & 07 & 179 & X45 \\
\hline$\cdot, 991$ & $\varepsilon, r q)$ & r, & 11 & v & rI & r,r & 1. & $r \wedge, \wedge$ & Av & oV,r & IVr & X46 \\
\hline$\cdot, \wedge \wedge 0$ & $\varepsilon, \Gamma \wedge \varepsilon$ & r, & 11 & $\varepsilon, \Gamma$ & r & $\varepsilon, r$ & Ir & ro,0 & $V V$ & r, & $1 \wedge 1$ & $\mathrm{X} 47$ \\
\hline$\cdot, \wedge 9 \Gamma$ & עrז, & $r, \tau$ & 11 & 0,7 & IV & $\varepsilon$ & Ir & $r 7, \Lambda$ & 11 & 09,9 & $|1|$ & $\mathrm{X} 48$ \\
\hline \multirow{2}{*}{. 940} & \multirow{2}{*}{ S, rTo } & $r, v$ & & $0, V$ & & $r, v$ & & $r v, q$ & & $\Delta \wedge, \wedge$ & & المعدل \\
\hline & & \multicolumn{3}{|c|}{$9, \varepsilon$} & & \multicolumn{2}{|c|}{$r, v$} & \multicolumn{4}{|c|}{$\wedge \uparrow, \vee$} & المجموع \\
\hline
\end{tabular}

ب- مسوحات رضا الزبائن: تثير النتائج الواردة في الجدول (T) إلى أن إجابات المبحوثين حول مسموحات

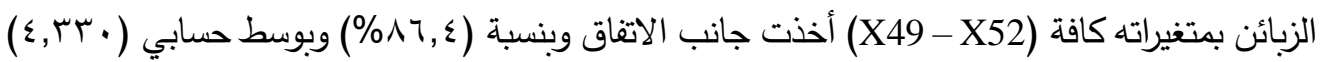

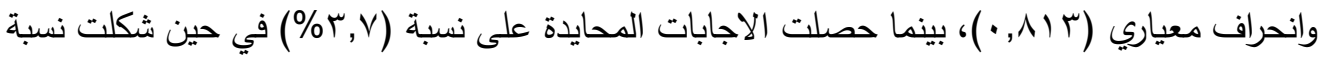
الاجابات السلبية غير المتقق عليها (१,〉\%)، وبما أن الإجابات أخذت اتجاه الاتفاق فان المتغير الذي أسهم في إغناء نسبة الاتفاق هو (X50) والذي ينص على (تتصل الثركة هاتفيا بعينة عشوائية من

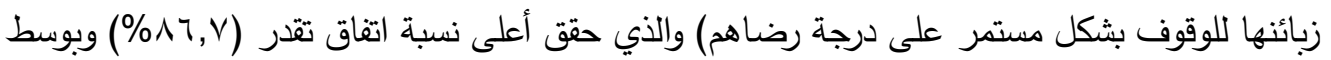

$$
\text { حسابي ( § }
$$




\section{رؤوف وسليمان}

الجدول (†): يبين التوزيعات التكرارية والنسب المئوية والاوساط الحسابية والانحرافات المعيارية لاجابات المبحوثين حول مسوحات رضا الزبون

\begin{tabular}{|c|c|c|c|c|c|c|c|c|c|c|c|c|}
\hline \multicolumn{12}{|c|}{ مقياس الاستجابة } & \multirow{3}{*}{ المتغيرات } \\
\hline \multirow{2}{*}{ الانحراف المعياري } & \multirow{2}{*}{ الوسط الحسابي } & \multicolumn{2}{|c|}{ لااتفق بثدة } & \multicolumn{2}{|c|}{ لا اتفق } & \multicolumn{2}{|c|}{ محايد } & \multicolumn{2}{|r|}{ اتفق } & \multicolumn{2}{|c|}{ اتفق بشدة } & \\
\hline & & $\%$ & ت & $\%$ & ت & $\%$ & $ت$ & $\%$ & 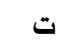 & $\%$ & ت & \\
\hline דיד, & $\varepsilon, r \cdot \tau$ & $\varepsilon$ & Kr & 7 & 11 & $r, \tau$ & 11 & $r \wedge, 0$ & NT & ov, $q$ & ivo & X49 \\
\hline •,VTr & $\varepsilon, T V \varepsilon$ & $\varepsilon$ & ir & 0,7 & IV & $r, \tau$ & 11 & $r \cdot, l$ & 91 & 07,7 & $|v|$ & X50 \\
\hline$\cdot, \wedge \leq 0$ & $\varepsilon, \Gamma \leqslant \varepsilon$ & $r, \tau$ & 11 & 7 & 11 & $r, \tau$ & 11 & ro, 1 & vA & $7 \cdot, 9$ & $1 \Lambda \varepsilon$ & X51 \\
\hline$\cdot, 9 \leq r$ & $\varepsilon, r q \wedge$ & $r, r$ & 1. & 7,7 & $r$. & $\varepsilon$ & ir & $r_{1,0}$ & 70 & $7 \varepsilon, 7$ & 190 & X52 \\
\hline \multirow{2}{*}{ זוז, • } & \multirow{2}{*}{$\varepsilon, \Gamma \Gamma$. } & $r, v$ & & 1 & & $r, v$ & & $r\rceil, \varepsilon$ & & 7. & & المعدل \\
\hline & & & & & $9, \vee$ & & $r, v$ & & & & $\wedge \uparrow, \varepsilon$ & المجموع \\
\hline
\end{tabular}

الجدول من إعداد الباحث بالاعتماد على برنامج (SPSS)

ج- التسويق الخفي: تثير النتائج الواردة في الجدول (V) إلى أن إجابات المبحوثين حول التسويق الخفي

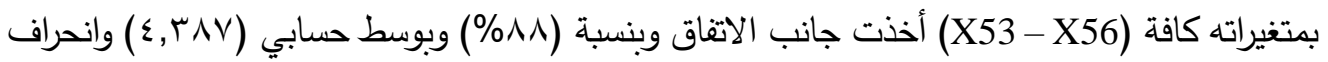

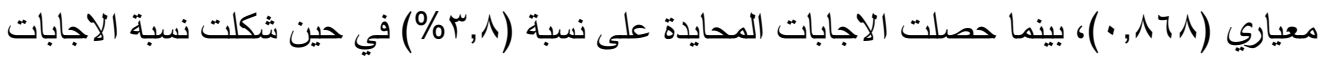

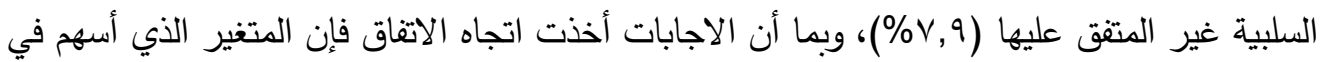
إغناء نسبة الاتفاق هو (X55) والذي ينص على ما يأتي (تستعين الثركة باشخاص ذو خبرة من خارج

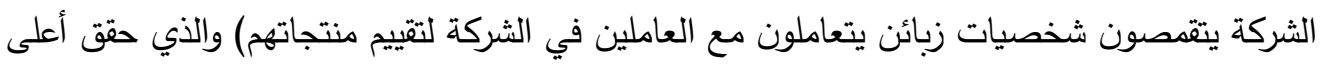

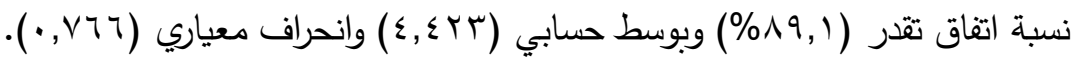
الجدول (V): يبين التوزيعات التكرارية والنسب المئوية والأوساط الحسابية والانحرافات المعيارية لإجابات المبحوثين حول التسويق الخفي

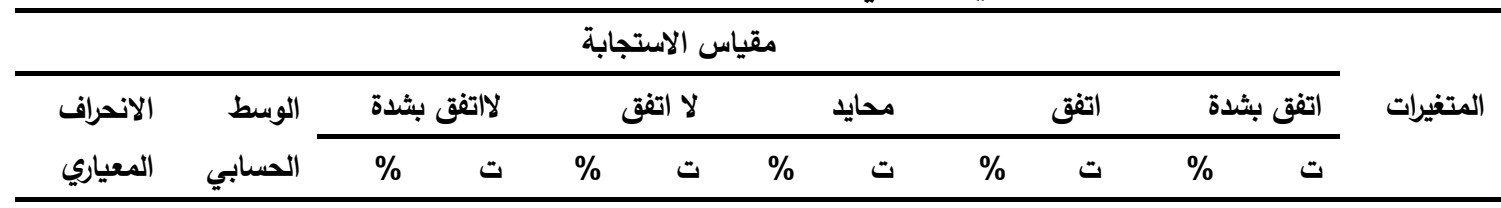


المر دور مرونة التصنيع في تعزيز رضا الزبون .إ.

\section{رؤوف وسليمان}

\begin{tabular}{|c|c|c|c|c|c|c|c|c|c|c|c|c|}
\hline$\cdot, \lambda r l$ & $\varepsilon, \Gamma \leqslant 1$ & $r, \tau$ & 11 & $0, r$ & 17 & $\varepsilon, 7$ & $1 \leqslant$ & $r T, r$ & 19 & $7 \cdot, r$ & IAr & X53 \\
\hline$\cdot, 994$ & $\varepsilon, \Gamma \vee V$ & 0 & 10 & r & 1. & $\varepsilon$ & Ir & $r \varepsilon, 0$ & $V \varepsilon$ & & 191 & X54 \\
\hline •, Vา & $\varepsilon, \varepsilon T r$ & $\varepsilon, \Gamma$ & Tr & r & 9 & $r, \tau$ & 11 & $r_{0,0}$ & $V V$ & ד,ד & 194 & X55 \\
\hline$\cdot, \wedge 97$ & $\varepsilon, \varepsilon 1$. & $\varepsilon, 7$ & $1 \leq$ & $r$ & 9 & r, & 1. & $r r, 0$ & $v_{1}$ & 70,7 & 191 & X56 \\
\hline \multirow{2}{*}{$\cdot, \wedge ५ \wedge$} & \multirow{2}{*}{$\varepsilon, r \wedge \vee$} & $\varepsilon, r$ & & $r, r$ & & $r, \Lambda$ & & $r \leq, q$ & & וT, & & المعدل \\
\hline & & & & & $v, q$ & & $r, \Lambda$ & & & & $\wedge \wedge$ & المجموع \\
\hline
\end{tabular}

الجدول من اعداد الباحث بالاعتماد على برنامج (SPSS) ثانيا: اختبار فرضيات البحث

ا - اختبار الفرضية الرئيسة الأولى: لا توجد علاقة ارتباط معنوي بين مرونة التصنيع ورضا الزبون على

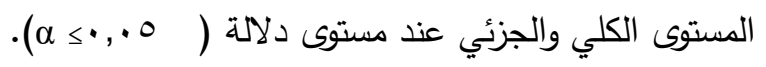

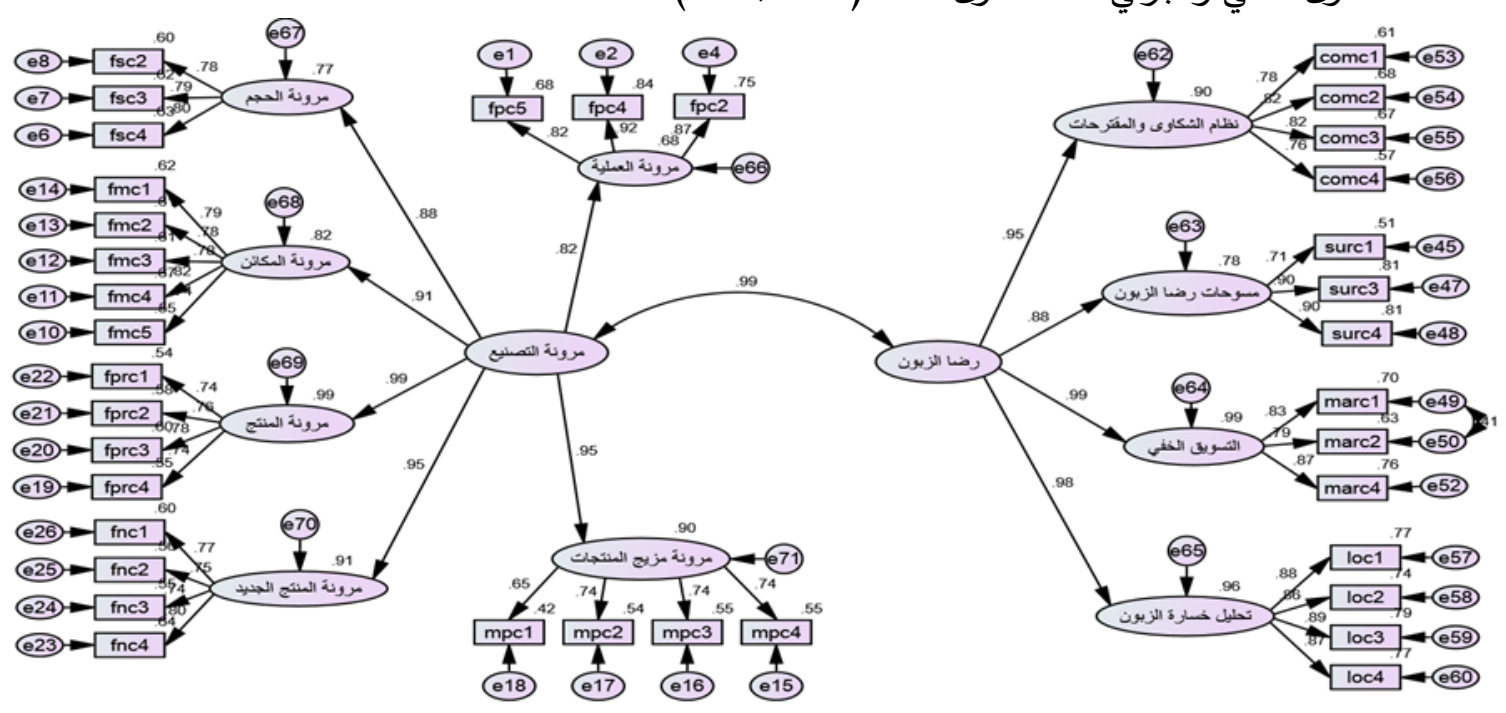

الثكل (ץ): الفرضية الأولى (علاقة الارتباط) بين رضا الزبون ومرونة التصنيع

ويوضح الجدول (^) قيم المعلمات المرتبطة بالأنموذج التي عن طريقها يتم قبول الفرضية الأولى قيد

الدراسة الحالية أو رفضها:

جدول(^): تحليل الارتباط الخاص بالفرضية الأولى

\begin{tabular}{|c|c|c|c|}
\hline Estimate & المتغيرات المؤثر بها & مسار التأثير & المتغيرات المؤثرة \\
\hline$\cdot .986$ & رضا الزبون & $\longleftrightarrow$ & مرونة التصنيع \\
\hline
\end{tabular}

TANMIYAT AL-RAFIDAIN (P-ISSN: 1609-591X; E-ISSN: 2664-276X) تنمية الرافدين 


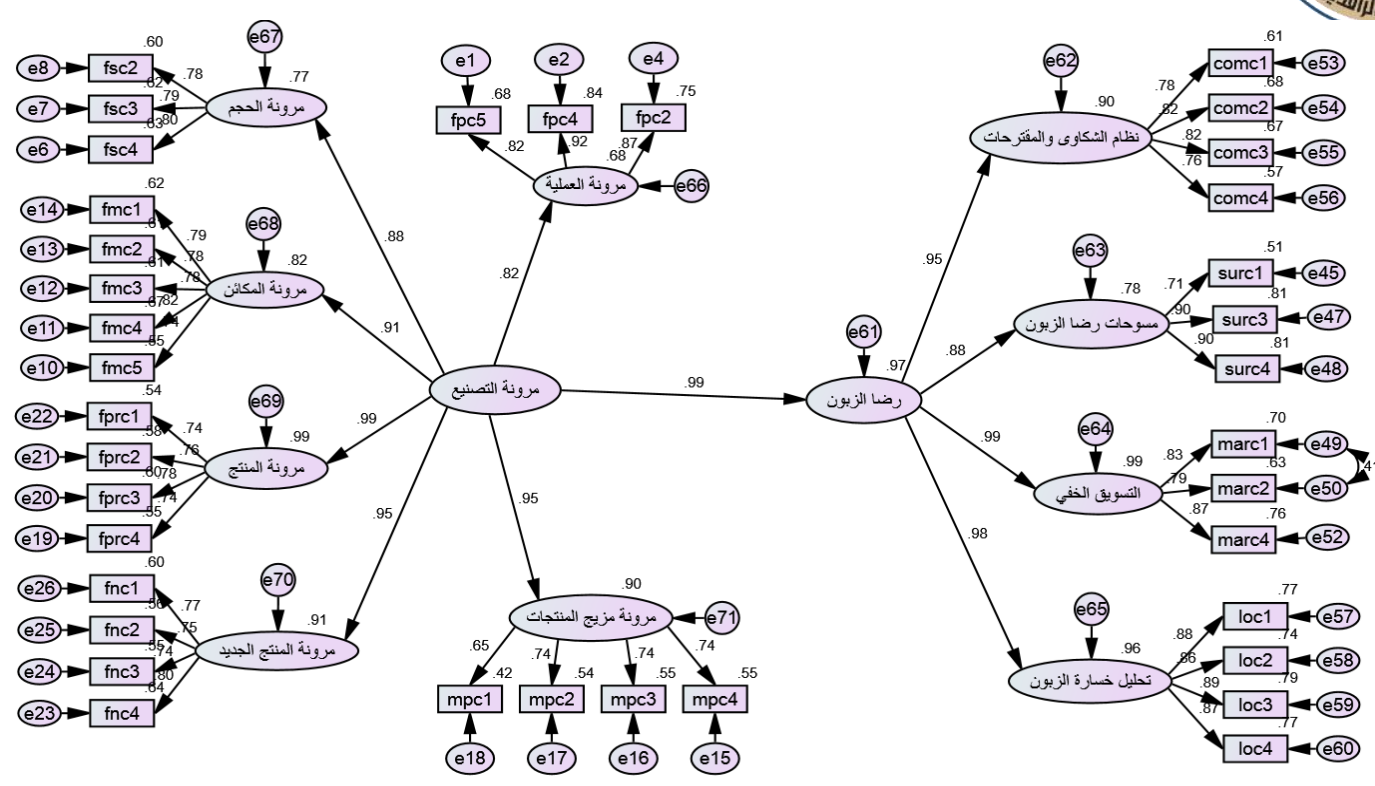

وبعد الاطلاع على معطيات الجدول (^) اتضح أن هناك علاقة ارتباط بين مرونة التصنيع و رضا

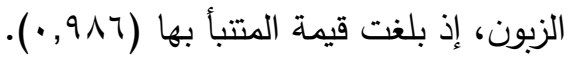
ومن هنا نرفض الفرضية الصفرية ونقبل الفرضية البديلة التي تتص على: توجد علاقة ارتباط معنوي بين مرونة التصنيع ورضا الزبون عند مستوى دلالة (0., •ـ $\alpha)$.

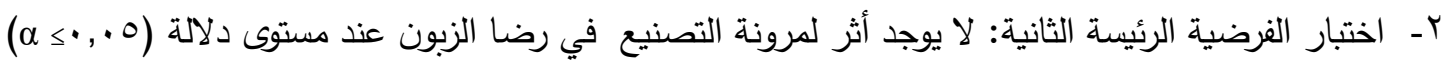
والثكل الآتي يوضتح ذلك

الثكل (ץ): الفرضية الاولى (أثر مرونة التصنيع في رضا الزبون)

ويوضح الجدول (9) قيم المعلمات المرتبطة بالأنموذج التي عن طريقها يتم قبول الفرضية الثانية أو رفضها: جدول (9): تأثير مرونة التصنيع في رضا الزبون Label P C.R. S.E. Estimate المتغيرات المؤثر بها

المتغيرات المؤثرة مسار التأثير 


مرونة التصنيع

ومن معطيات الجدول(9) نلاحظ أن معامل تأثير مرونة التصنيع في رضا الزبون بلغت قيمته المتنبأ بها

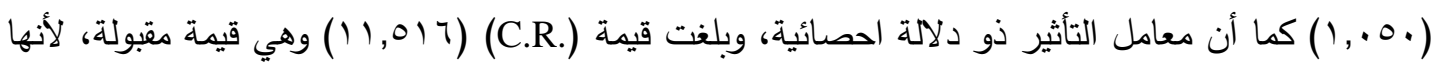

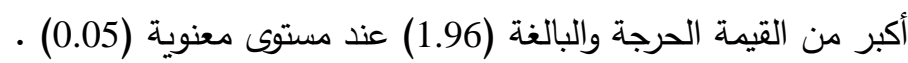
ومن هنا نرفض الفرضية الصفرية ونقبل الفرضية البديلة التي تتص على: يوجد أثر معنوي لمرونة التصنيع في رضا الزبون عند مستوى دلالة (0. , • $\alpha)$.

$$
\begin{array}{r}
\text { أولاً: الاستتثث الرابع: الاستنتاجات والمقترحات } \\
\text { ألتنتاجات الجانب النظري }
\end{array}
$$

1- تعد مرونة التصنيع عاملا مهما لزيادة كفاءة الثركة وتحسين مستوى أدائها. r- يمثل رضا الزبون غاية تسعى الشركة لتحقيقها عبر أدوات عدة يمكن لمرونة التصنيع أن تكون أحد تلك

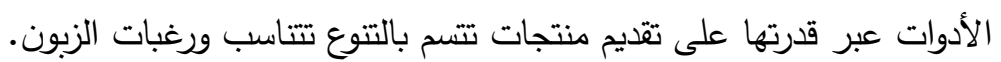

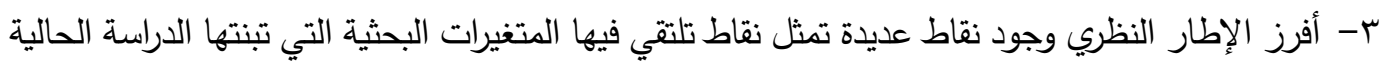
والتي يمكن الاعتماد عليها لتبرير منطقية العلاقة بين المتغيرات البحثية.

$$
\text { ب- استنتاجات الجانب العملي }
$$

في ضوء تحليل نتائج البيانات التي تم الحصول عليها توصل الباحثان إلى عدد من الاستتتاجات والتي يمكن توضيحها وكالاتي: 1- تبين النتائج حصول الثركة قيد البحث على أعلى مستوى من المرونة التصنيعية تمثل في أبعاد (مرونة المكائن، ومرونة المنتج و مرونة المنتج الجديد) إذ بلغ المعدل (^,0) لكل منهما، وهي نسبة جيدة جدا، كما حصل (X13) في مرونة المكائن على أعلى نسبة تقدر بـ (^V, ) والذي ينص (يمكن للمكائن الانتقال من عملية إلى أخرى من دون تحمل تكاليف تشغيل إضافية) وهذا يدل على امتلاك الشركة المبحوثة لمكائن لايها القدرة على تتفيذ أعمال مختلفة وبمستوى جيد من الكفاءة. ץ- حصلت مرونة العملية على المرتبة الثانية في الثركة المبحوثة، إذ بلغ مجموع المعدل (؟ (10) وهي نسبة جيدة جدا كما حصل (X1) على أعلى نسبة اتفاق تقدر (^o,^) وهذا يشير إلى امتلاك الثركة مستوى عال

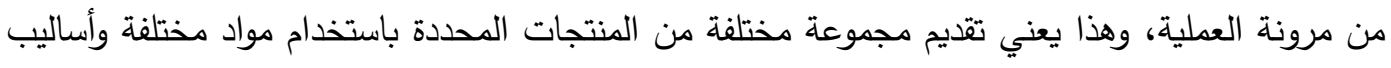
عمل مختلفة، وأن الغرض من مرونة العملية هو لتقليل أحجام مجموعات الإنتاج وتقليل تكاليف المخزون. 
r- تحقيق بعد مرونة الحجم على المرتبة الثالثة حيث بلغت النسبة في مجموع المعدل (10,0) مما يدل على انها نسبة جيدة جدا كما حصل (X6) على اعلى نسبة تقدر بـ (^o,^) والذي ينص على أنه (يمكن تحقيق ربحية عند إنتاج أحجام مختلفة) وهذا يعني أن الثركة المبحوثة لديها القدرة على تقديم منتجات بأحجام مختلفة

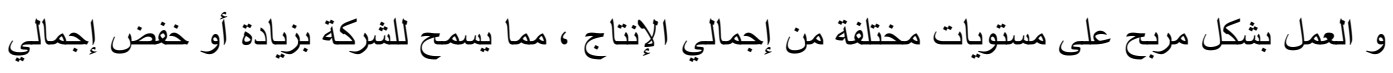
حجم الإنتاج بطريقة مناسبة للتغيير في طلب الزبائن. ع- فيما يتعلق بالأثر والارتباط بين متغيرات الدراسة، تثنير النتائج إلى وجود علاقة أثر معنوي بين مرونة

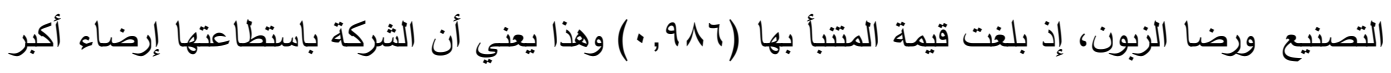

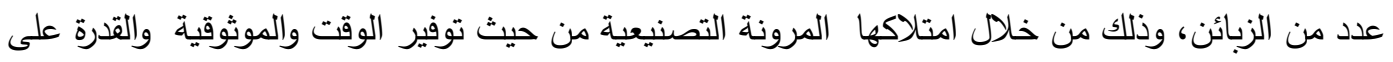
تلبية متطلبات الزبائن بانتاج منتجات متتوعة وبحسب التغيرات الحاصلة في السوق مع المحافظة على الموقع التتافسي وجودة المنتجات. ثانيا: المقترحات استكمالاً للمتطلبات المنهجية وفي ضوء الاستتتاجات التي تم إيرادها ، فقد وُجِد من المناسب تقديم مجموعة من المقترحات التي يمكن أن تساعد الثركات المبحوثة في توظيف أبعاد مرونة التصنيع في تحقيق

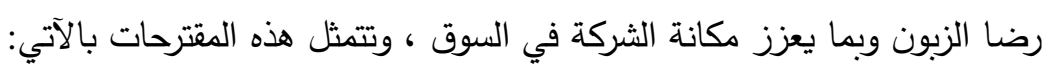

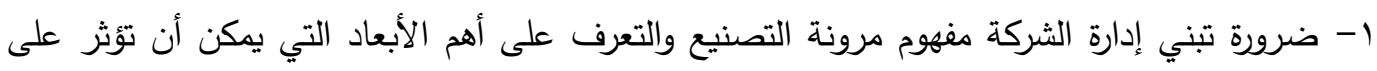
أدائها كما ينبغي على الثركات المبحوثة إعطاء المزيد من الصلاحيات للعاملين والحرفيين للقيام بالتحسينات المستمرة من خلال المساعدة في إجراء تعديلات وإضافة احجام حديثة للمنتجات.

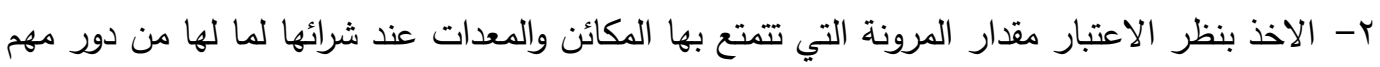
في تحقيق الثركة مرونة التصنيع، كما يجب أن تهتم الثركات المبحوثة بتوفير المعدات والأدوات التي يتم استخدامها من أجل الفحص والكثف عن الأخطاء والعيوب في كل خطوة من خطوات العملية الانتاجية، وذلك للاستمرار في إنتاج منتجات بمرونة عالية وبما يلائم متطلبات الزبائن.

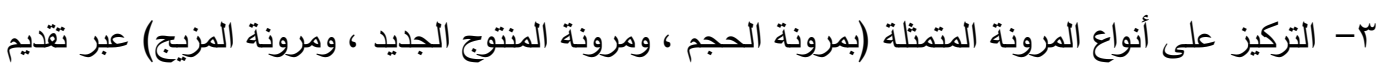

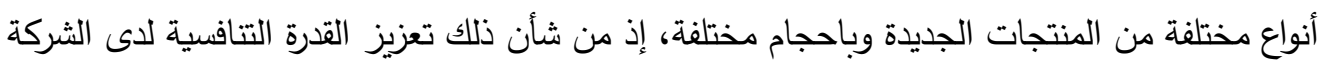
كما ينبغي اهتمام الثركات المبحوثة بحذف الأنشطة والمهام التي تكون سبباً في إضاعة الوقت والجهد إنهان والمواد التي لا تضيف أي قيمة في كل نشاط أو مرحلة من مراحل الانتاج.

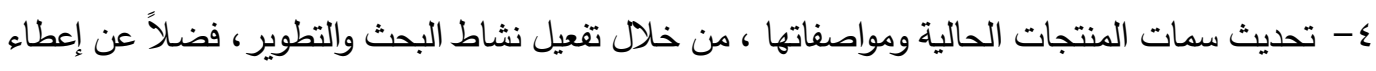
المزيد من الاهتمام من قبل الشركات المبحوثة بتوفير دورات تدريبية مستمرة للعاملين في ظل التطور 
الحاصل في التكنولوجيا ومواكبة تلك التغيرات للتعامل مع المكائن الحديثة المختلفة التي تستخدم في

$$
\text { إنتاج المنتجات البلاستيكية والالمنيوم. }
$$

\section{Referncess}

Abdul-Karim, Azzam Abdel-Wahab, Muhammad, Rosh Ibrahim, (2019), "The Impact of the Company's Ownership of the Core Capabilities in Enhancing Manufacturing Flexibility: An Applied Study in the General Company for Construction Industries", Anbar University Journal of Economic and Administrative Sciences, Volume (11), Issue (24).

Al-Afandi, Hassan Talal Ahmad, (2018), "The Sequential Impact of Green Purchasing Strategies and Green Manufacturing Requirements on Customer Satisfaction: An Exploratory Study of Managers' Opinions in a Group of Furniture Industry Companies in Mosul ", Master Thesis in Industrial Management - College of Administration and Economics, University Mosul.

Al-Azzawi, Faris Salah, Al-Sabawi, Israa Waad Allah Qasim, (2019), "The Role of Total Environmental Quality Management in Flexible Manufacturing: An Exploratory Study in Badoush Cement Factory," Journal of Economic and Administrative Sciences, University of Baghdad, Vol (25), Issue (110).

Al-Fraan, Ali Zakaria Farhan, (2007), "The Impact of Manufacturing Flexibility on Competitive Advantage: A Field Study in Furniture Manufacturing Companies Operating in King Abdullah II Industrial City - Sahab", Master Thesis (unpublished), Al-Bayt University .

Al-Lami, Ghassan Qassem Dawood, Jawad, Kazem Ahmad, (2014), "Determining the Level of Manufacturing Flexibility, a Field Study in the General Company for Cotton Industries", Baghdad College of Administrative and Economic Sciences Journal, Issue (41)

Al-Muhtadi, Munther Khader Yaqoub, (2003), "The Role of Hotel Services Marketing Information System in Enhancing Customer Satisfaction: A Case Study of Jian Hotel in Duhok Governorate", unpublished Master Thesis, College of Administration and Economics, University of Mosul.

Al-Taie, Ali Hassoun, (2007), "Diagnosing the Core Capabilities in Governmental Companies: A Comparative Study in Baghdad Teaching Hospital and the General Company for Battery Industry", Journal of Economic and Administrative Sciences, Vol (13), No. (45).

Bateman, N., Stockton, D., Lawrence, P., (1999) "Measuring the mix response flexibility of manufacturing systems", International Journal of Production Research 37(4): p. 871-880.

Beckman, S.L. \& Rosenfield, D.B. (2008), "Operations Strategy :Competing in the 21st century", Mc Graw - Hill/Irwin, Inc.

Hamad, Amer Ali, (2018), "The Role of Innovative Promotional Mix Elements in Customer Satisfaction: An Exploratory Study of the Views of a Sample of Users of Asia Cell

TANMIYAT AL-RAFIDAIN (P-ISSN: 1609-591X; E-ISSN: 2664-276X) تنمية الرافدين 
Services for Mobile Communications," Baghdad College of Economic Sciences Journal, Issue (51)

Kotler, Philp, (2000), " Marketing management ", 5th ed., Prentice-Hall, New Jersey, USA.

Mahmoud, Othman Karim, (2016), "The Role of Green Manufacturing Practices in Improving the Flexibility of Operations: An Analytical Study of the Opinions of a Sample of Restaurant Workers in the City of Sulaymaniyah", Tikrit Journal of Administrative and Economic Sciences, Volume (12), Issue (35).

Mehdi Khoobiyan, Alireza Pooya, Ahmad Tavakkoli, Fariborz Rahimnia,(2017)K” Taxonomy of Manufacturing Flexibility at Manufacturing Companies Using Imperialist Competitive Algorithms, Support Vector Machines and Hierarchical Cluster Analysis”, Engineering, Technology \& Applied Science Research Vol. 7, No. 2, 2017, 1559-1566.

Nayak, Narayan C., and Ray, Pradip K., " An Improved Methodology for Flexibility Design in production System of Manufacturing Firms" ,International Refereed Journal of Engineering and Science, Vol 2, Issue $12,2013$.

Ngamsirijit, Wuttigrai .," Manufacturing Flexibility Improvement: Case Studies and Survey of Thai Automotive Industry. $\mathrm{PhD}$ thesis, University of Nottingham" ,Thesis submitted to the University of Nottingham for the degree of Doctor of Philosophy, 2008

Nilsson, Carl-Henric .,"On Strategy And Manufacturing Flexibility", Published by : Department of Industrial Engineering Lund Institute of Technology,ISBN 916281500-, 2nd printing, Printed in Sweden, 1995

Nujoud, Hatem, (2006), “Activating the customer's satisfaction as a strategic entry point to build his loyalty: a case study in the new Algerian plant for canning products", Master Thesis, Faculty of Economic Sciences and Management Sciences, Algeria.

Parker, R.P. and Wirth A. (1998), "Manufacturing Flexibility :Measures and Relationships", European Journal of Operational Research ,118, pp. 429-449

Sethi, A., Sethi, S., (1990) "Flexibility in Manufacturing: A Survey" The International Journal of Flexible Manufacturing Systems 2,: p.289-328

Shailendra Kuma, Ajay Goyal, Ankit Singhal, (2017), "Manufacturing Flexibility and its Effect on System Performance" Volume 11 Number 2, April. 2017.

TANMIYAT AL-RAFIDAIN (P-ISSN: 1609-591X; E-ISSN: 2664-276X) تنمية الرافدين 